In press at Perception (2017)

\title{
Effect of biological relatedness on perfume selection for others: Preliminary evidence.
}

\author{
Markéta Sobotková ${ }^{1}$, Jitka Fialová ${ }^{1,2}$, S. Craig Roberts ${ }^{3}$, Jan \\ Havlíček ${ }^{1,2}$
}

Short title: Biological relatedness and perfume selection

Article type: Regular paper

${ }^{1}$ Faculty of Science, Charles University, Prague, Czech Republic

${ }^{2}$ National Institute of Mental Health, Klecany, Czech Republic

${ }^{3}$ School of Natural Sciences, University of Stirling, Stirling, UK

Corresponding author: Jan Havlíček, Department of Zoology, Faculty of Science, Charles

University, Viničná 7, Prague 2, 12844, Czech Republic.

Email: jhavlicek@natur.cuni.cz 


\section{Abstract}

People tend to choose perfumes to complement their body odour. As kin share some body odour qualities, their ability to select complementary perfumes for relatives might be higher compared to selection for non-relatives. We tested this in two studies, comparing selection of a perfume for a target man by himself and by either a familiar but unrelated individual (girlfriend; Study 1) or a relative (sister; Study 2). Target men applied the two perfumes (own/other's choice) to their axillae and then wore cotton pads for $12 \mathrm{~h}$. Collected perfumebody odour blends and perfumes alone were assessed by rater panels. In Study 1, the blends were rated as nominally more pleasant when body odours were mixed with the perfumes selected by girlfriends compared to those selected by target men themselves. In Study 2, body odours mixed with perfumes selected by sisters were rated significantly more attractive than those mixed with perfumes selected by target men. No significant differences were found for attractiveness and pleasantness ratings when perfumes were rated alone, suggesting that it was the resulting blends that were uniquely different. Our results indicate that sisters might be particularly tuned to select suitable perfumes for their siblings.

Keywords: body odour, fragrance choice, chemical communication, smell, kinship 


\section{Introduction}

Humans appear to use chemical cues in various social contexts ranging from individual and kin recognition (Weisfeld, Czilli, Phillips, Gall \& Lichtman, 2003; Lenochova \& Havlicek, 2008), affective states (Fialová \& Havlíček, 2012), personality judgments (Sorokowska, Sorokowski \& Szmajke, 2012; Sorokowska, Sorokowski \& Havlíček, 2016), mother-infant interactions (Russell, Mendelson \& Peeke, 1983; Cernoch \& Porter, 1985) to job interviews (Baron, 1983; Sczesny \& Stahlberg, 2002). The most extensively studied context in human chemical communication is undoubtedly the one regarding mate choice. It has been shown that body odour might provide cues to a host of biologically relevant qualities, including actual fertility (Kuukasjärvi et al. 2004; Havlíček, Dvořáková, Bartoš \& Flegr, 2006), developmental stability in terms of lower fluctuating asymmetry (Thornhill \& Gangestad, 1999; Thornhill et al., 2003), health (Olsson et al., 2014; Shirasu \& Touhara, 2011), diet

(Fialová, Roberts \& Havlíček, 2016), visually assessed attractiveness (Roberts et al., 2011), facial masculinity (Allen, Cobey, Havlíček \& Roberts, 2016) and genetic compatibility (Havlicek \& Roberts, 2009).

Interestingly, there is also ample cross-cultural and historical evidence showing an almost universal human tendency to modify body odour using various fragrances. The use of fragranced substances for "olfactory adornment", often produced by sophisticated technologies, is documented from several ancient civilizations such as in Egypt and Mesopotamia, and later in Greece and Rome (Stoddart, 1990; Havlíček \& Roberts, 2013). 
In contemporary Western societies, body odour is frequently considered to be repugnant, and people invest relatively large amounts of money in cosmetic products which are aimed to modify or minimize their body odour. For example, estimated total sales in the fragrance and flavour industry increased from $\$ 12,9$ billion in 1999 to $\$ 23,9$ billion in 2013 (Anon., 2014). Furthermore, fragrances affect the outcomes of social interactions and significantly contribute to first impression formations. For example, candidates who used perfumes for a job interview were more likely to be hired (Baron, 1986), especially when evaluated by women (Baron, 1983). Furthermore, it has been shown that impressions of others may be affected even without odour being actually accessible to the judges (e.g., based on video ratings), perhaps because it affected the self-confidence of the fragrance wearer and consequently also his attractiveness (Roberts et al., 2009).

It is generally assumed that perfumes mask or hide body odour and thus tends to minimize the potential for communication via body odour. This is supported by a study showing that the use of cosmetic products prevented correct judgments of gender based on body odour (Schleidt, 1980). However, if the sole purpose of perfume use is body odour masking, why should such a large variability in preferences for fragrances exist across individuals? One answer is that fragrances might not mask body odour but rather interact with body odour in a complementary fashion. This hypothesis was first tested by Milinski and Wedekind (2001), who asked participants to rate the preferred perfume ingredients for themselves and for their potential partner. These participants had been previously genotyped at the major histocompatibility complex (MHC). As products of MHC genes affect human body odour, 
one may expect that individuals sharing the same MHC alleles would also show similar fragrance preferences. Interestingly, Milinski and Wedekind (2001) found a correlation between MHC genes and fragrance preferences when the participants rated the ingredients for themselves, but not for their partners. A similar pattern was later observed by Hämmerli, Schweizgut, and Kaegi (2012). These findings lend support to the idea of perfume selection being influenced by how the perfumes may complement the odour of the body to which they will be applied.

This interaction between body odour and fragrances was recently explored by Lenochová et al. (2012) in three experiments. The logic of the study was as follows. If fragrances mask body odour, the perfumed odour samples should show lower individual variability compared to the non-perfumed odour samples. However, should body odour and perfume interact, the variability in hedonic ratings would be retained in the perfumed samples. In two of these experiments, hedonic ratings of perfumed and non-perfumed body odour samples, obtained from the same groups of odour donors, were compared. Lenochová et al. found that the variability of the perfumed body odour samples did not decrease as expected according to the masking hypothesis. Furthermore, the third experiment showed that samples of body odour with a perfume that an individual chose for himself were rated as more pleasant than samples blended with a perfume assigned randomly. Together, these findings indicate that the interactive nature of the body odour-perfume blends provides an explanation for idiosyncratic variation in perfume choice, and moreover that fragrance use may not preclude communication via body odour. Indeed, it was recently shown that using 
one's own fragrance as compared to an assigned fragrance increased individual recognition of body odour-perfume blends (Allen, Havlíček \& Roberts, 2015).

In this paper, we present results of two independent studies which aimed to refine our understanding of individual perfume choice in relation to biological relatedness. Previous research indicates that the resulting qualities of a perfume-body odour blend are difficult to predict from smelling the fragrance alone (Lenochová et al. 2012). Furthermore, several lines of evidence show that genetically related individuals share similarities in their body odour (Porter, Cernoch \& Balogh, 1985; Roberts et al., 2005; Weisfeld et al., 2003). Thus, one might expect people to use their own body odour as a reference marker when selecting a perfume to give to a relative. Based on these points, we hypothesized that a resulting perfume-body odour blend would be of similar attractiveness if the perfume was selected by a biological relative or the individual himself. On the other hand, if the perfume was to be selected by a non-relative, the resulting blend would be of lower attractiveness compared to the selection made by the individual himself. In Study 1, we compared hedonic ratings of male axillary odour blended with a perfume selected either by the target man or by his girlfriend. In Study 2, employing an identical research design, the perfume selection was made by the target man and his sister. We selected female romantic partners as representative of non-relatives and sisters as representatives of the relatives in order to keep gender, age and familiarity as comparable as possible across the two studies. Finally, to test whether the differences in ratings of body odour-perfume blends are not due to the 
perceptual quality of the perfumes themselves, in both studies we performed additional rating sessions of the perfume samples alone.

\section{Materials and methods}

\subsection{Study 1}

\subsubsection{Participants}

\section{Odour donors}

Sixteen men were recruited using flyers distributed among the students of Charles University in Prague or via an online advertisement. As the perfume choice in four of these men was identical with the choice their romantic partners made, only the samples from one randomly selected man were used as a control and the samples obtained from the other three men were discarded from the study. The mean age of the thirteen remaining men was 23.9 years $(\mathrm{SD}=2.9$, range 18 to 30 years). Six men reported that they shaved their armpits regularly. Although shaving may alter body odour, this practice should not systematically affect the results in this study as we employed a within-subjects design.

All participants were non-smokers, reported no olfactory impairment or dermatological disease, and, to maximize chances of being well acquainted with their partner body odour, had been in the relationship with their current partners for at least 6 months (mean 
relationship length $=33.3$ months, $\mathrm{SD}=15.9$ ). To avoid the possibility that men chose perfumes based simply on their familiarity, only the men who reported not normally using perfumes (this restriction did not apply to deodorants and antiperspirants) were recruited. For their time, travel costs, and potential inconvenience caused by the prescribed diet, each man was reimbursed with $300 \mathrm{CZK}$ (approx. $11 €$ ).

\section{Partners of donors}

Through the male participants, we further recruited 13 female partners of the odour donors (mean age $=23.2$ years; $\mathrm{SD}=2.4$; range 18 to 26 years), none of whom reported olfactory impairment. All but one were using hormonal contraception. As women were tasked with selecting perfumes for their romantic partner and not for themselves, we did not restrict our recruitment only to those who do not normally use perfumes, as we had done with the men. Each woman was given $100 \mathrm{CZK}$ (approx. $4 €$ ) in compensation for travel costs and their time.

\section{Raters}

Twenty female raters (mean age 22.3 years; $\mathrm{SD}=2.3$; range 19 to 27 years) were recruited either personally among the students of Charles University in Prague or via an online advertisement to rate body odour-perfume blends. None reported olfactory impairment, and we recruited only hormonal contraceptive users to avoid possible fluctuations in olfactory perception across the menstrual cycle (Martinec Nováková, Havlíček \& Roberts, 2014). To 
avoid a possible familiarity effect on hedonic ratings of the resulting perfume-body odour blend, we recruited only the raters unfamiliar with the target men.

Using the same approach, we recruited an additional 20 women (mean age $=22.6$ years; SD $=3.2$; range 18 to 30 years) and 22 men (mean age $=24.6$ years; $\mathrm{SD}=3.6$; range 21 to 35 years) to rate the pure perfume samples. Men and women did not significantly differ in their age. All women were hormonal contraception users. All raters were reimbursed with 100 CZK (approx. $4 €)$.

All procedures followed were in accordance with the ethical standards of the institutional committee on human experimentation and with the Helsinki Declaration of 1975, as revised in 2008 (5). The study was approved by the IRB of Charles University, Faculty of Science (Approval Number 2012/7). All participants provided written informed consents.

\subsubsection{Perfumes}

In order to ensure that we included a representative range of male perfumes available on the market, a set of perfumes was chosen in collaboration with professional perfumers (from the company Seven Scent). The set consisted of 24 perfumes which were classified into six categories according to the OSMOZ classification (www.osmoz.com): fougère, woody, aquatic, citrus/cologne, oriental, aromatic. These main categories are further divided into 
four subcategories, and each of the perfume selected is considered to be prototypical of one particular subcategory (see Table 1).

Table 1: The classification system used and perfumes representing each subcategory. Classification consists of 6 main categories and each category is further characterized by 4 subcategories.

\begin{tabular}{|c|c|c|}
\hline Category & Subcategory & Perfume \\
\hline \multirow{4}{*}{ fougère } & fougère & 1 - J. P. Gaultier - Le Male (1985) \\
\hline & fougère-aromatic & 7 - Gucci - Guilty pour Homme (2011) \\
\hline & fougère-aquatic & 8 - Esteé Lauder - Pleasures for Men (1998) \\
\hline & fougère-ambery & $9-$ Boss - In Motion (2002) \\
\hline \multirow{4}{*}{ woody } & woody & 2 - Dior - Fahrenheit (1988) \\
\hline & woody-ambery & 10 - Joop! - Joop Homme (1989) \\
\hline & woody-spicy & 11 - Paco Rabanne - 1 Million (2008) \\
\hline & woody-aromatic & 12 - Ralph Lauren - Polo Black (2005) \\
\hline \multirow{4}{*}{ aquatic } & aquatic & 3 - Davidoff - Cool Water (1988) \\
\hline & aquatic-citrus & $\begin{array}{l}13-\text { Armani - Acqua Di Gio pour Homme } \\
(1996)\end{array}$ \\
\hline & aquatic-fougère & 14 - Calvin Klein - Euphoria Men (2006) \\
\hline & aquatic-woody & 15 - Kenzo - For Men (1991) \\
\hline \multirow{4}{*}{ citrus/cologne } & citrus & 4- Azzaro- Chrome (1996) \\
\hline & citrus-aquatic & $\begin{array}{l}16 \text { - Dolce Gabbana - Light Blue p. Hom. } \\
(2007)\end{array}$ \\
\hline & citrus-chypre & 17 - Dior - Eau Sauvage (1966) \\
\hline & citrus-floral & 18 - Calvin Klein - One (1995) \\
\hline \multirow{4}{*}{ oriental } & oriental & 5 - Calvin Klein - Obsession for Men (1986) \\
\hline & oriental-woody & 19 - Guess - Seductive Homme (2011) \\
\hline & oriental-citrus & 20 - Guerlain - Habit Rouge (1965) \\
\hline & oriental-fougère & $\begin{array}{l}21 \text { - Chanel - Allure Homme Sport Eau Ex. } \\
(2012)\end{array}$ \\
\hline \multirow{2}{*}{ aromatic } & aromatic & 6 - Calvin Klein - Eternity for Men (1989) \\
\hline & aromatic-chypre & 22 - Yves Saint Laurent - Kouros (1981) \\
\hline
\end{tabular}




\begin{tabular}{|l|l|l|}
\hline & aromatic-leather & $23-$ Chanel - Antaeus (1981) \\
\cline { 2 - 3 } & aromatic-woody & $24-$ Cristian Audiger- Ed Hardy (2008) \\
\hline
\end{tabular}

\subsubsection{Experimental design}

\section{Perfume selection}

Each donor and his partner arrived at our laboratory separately, at arranged times. The perfume samples were applied onto cotton pads fixed to a strip of card (to facilitate manipulation). This was done in a separate room to avoid any background odour pollution, immediately before the assessment to prevent any fragrance deterioration. All perfume samples were presented in the standardized amount of one squirt of each perfume per pad.

We developed a two-step selection procedure to avoid olfactory adaptation that would likely occur if the participants were to assess all 24 perfume samples at once. In the first step, they were presented with 6 perfumes - each representing one main perfume category: fougère - Le Male, woody - Fahrenheit, aquatic - Cool Water, citrus/cologne Chrome, oriental - Obsession for Men, aromatic - Eternity for Men. In this step, men were asked to choose the two perfumes they would like to wear the most. In the analogous test, women were asked to choose the two perfumes they felt would best suit their partners.

The participants then had a short break, during which they completed a set of questionnaires: a demographic questionnaire, the Dyadic Adjustment Scale (DAS) 
(Spanier, 1976), and a short questionnaire consisting of items on sexual satisfaction, sexual rejection, compliant sex, and attractiveness of partner (Garver-Apgar, Gangestad, Thornhill, Miller \& Olp, 2006).

In the second step, participants were presented with 4 perfumes representing subcategories of each of the two main categories selected in the first step ( 8 perfumes overall). From these samples, each man again selected one perfume which he would like to wear the most, and each woman selected one perfume which she felt would best suit her partner. The selected perfume was then used in the subsequent parts of the study. Figure 1 provides an example of this two-step procedure. In this example, the participant selected Cool water (category aquatic) and Obsession for Men (category oriental) as the two most preferred perfumes in the first step. In the second step, the experimenters presented the participant with further 8 samples (four from the aquatic category and four from the oriental category) and ask the participant to select the one most suitable for himself/her partner.

\section{Odour collection}

Several days before the odour sampling, each participant received a written list of instructions and restrictions for the day prior to and the day of sampling. Men were instructed to refrain from 1) drinking alcoholic beverages or using other drugs, 2) eating spicy food or meals containing garlic, onion, chilli, pepper, vinegar, blue cheese, cabbage, radish, fermented milk products, and marinated fish, 3) using perfumes, deodorants, 
antiperspirants, aftershave, and shower gels and 4) exaggerated physical activities, sexual activity, and sleeping in the same bed with their partner or their pet (on the day of the sampling). The list of restrictions is similar to several previous studies (Havlicek \& Lenochova, 2008; Lenochova, Roberts \& Havlicek, 2009; Kohoutová, Rubešová \& Havlíček, 2012; Roberts, Petrie \& Havlíček, 2013).

The male donors arrived at the laboratory between 6 and 7 pm. Each donor was provided with a package which contained a bar of non-perfumed soap, two spray flacons (one containing the perfume selected by male donor himself, the other selected by his partner), two cotton pads (elliptical in shape, approximately $9 \times 7 \mathrm{~cm}$ at their longest axis, Ebelin cosmetic pads, DM-drogerie markt, www.dm-drogeriemarkt.cz, Prague), a 100\% cotton Tshirt, a plaster, a surgical tape (Omnipur, DM-drogeriemarkt, www.dm-drogeriemarkt.cz, Prague), and two zip-lock plastic bags for storing the pads from both armpits.

Subsequently, donors went to the bathroom where they washed both their armpits with the non-perfumed soap and sprayed one splash of perfume into each armpit. The side of armpit treatment was randomly selected by the researcher to avoid the possible effect of armpit side (Ferdenzi, Schaal \& Roberts, 2009). Donors then fixed the cotton pad to each armpit using the surgical tape and wore the provided white T-shirt as the first layer of clothing, to minimise the odour contamination from their own clothing or other extrinsic ambient 
odours. On their departure, donors were reminded about the restrictions that they should be following during the sampling period.

Donors wore the cotton pads for $12 \mathrm{~h}$ (during the night) — this period was previously shown to be sufficient for obtaining odour samples for assessment by raters (Havlíček, Lenochová, Oberzaucher, Grammer \& Roberts, 2011). On the next morning, donors returned to the laboratory, removed the cotton pads, and put them into the corresponding zip-lock plastic bags. The samples were immediately frozen - this method has no detectable impact on perceptual quality of the odour samples (Lenochova et al., 2009). Donors also completed a questionnaire to check for their conformity with the instructions. Two donors reported they slept in the bed with their partner during the sampling; one of those two slept in the bed also with a pet. One donor reported having a meal which contained garlic and another consuming a small amount of alcohol.

\section{Rating session}

The rating session for the body odour-perfume blends was performed six weeks after the sample collection. It took place in a quiet, ventilated room with relatively constant temperature (about $21^{\circ} \mathrm{C}$ ) and humidity (about $40 \%$ ). Stimuli (the pads) were taken out of the freezer two hours before the onset of the rating session, and were enclosed in $250 \mathrm{ml}$ opaque jars labelled by a code. 
The stimuli were split into 2 sets. Each participant rated both sets (i.e., 26 stimuli in 13 pairs). The order of sets and the order of the stimuli within a set were both randomized. The samples from each donor were presented in pairs and rated in the form of a forced-choice test (i.e., the raters were instructed not to use the same value within each pair). Stimuli were rated on a 7-point scale for their 1) intensity, 2) pleasantness, 3) attractiveness, and 4) masculinity. Both ends of each scale were anchored by verbal descriptions (e.g., very unpleasant to very pleasant). Ratings were written down immediately after sniffing each stimulus, but the time spent sniffing was not restricted. Raters were given a break of approximately 10 min between the 2 sets to avoid possible odour adaptation. During the break, they were offered mineral water and asked to complete an additional questionnaire.

A separate rating session was organized for the assessment of the pure perfume samples. The perfumes were applied to cotton pads (one squirt of perfume for each cotton pad) and encased in $250 \mathrm{ml}$ opaque jars. Other aspects of the rating session were also identical to the ratings of the body odour-perfume blends. However, here the samples were assessed by both men and women; this enabled us to detect possible differences in perfume preferences between men and women.

\subsection{Study 2}

\subsubsection{Participants}




\section{Odour donors}

Twelve men (mean age $=22.2$ years, $\mathrm{SD}=2.8$, range 18 to 29 years) were recruited using flyers distributed among the students of Charles University in Prague or via an online advertisement. All of them were non-smokers, reported no olfactory impairment or dermatological disease, and were full siblings with the participating sister. Nine of them reported regularly shaving their armpits. To avoid perfume selection being affected by the familiarity of perfumes, we recruited only men who commonly do not use perfumes (this

restriction did not apply to deodorants and antiperspirants). For their time, travel costs, and potential inconvenience caused by the prescribed diet, each man obtained CZK 300 (approx. $11 €$ ).

\section{Sisters of donors}

Twelve women — sisters of the donors — were recruited through their participating brothers; their mean age was 22.4 years ( $\mathrm{SD}=3.6$; range 18 to 28 years). All of them reported no olfactory impairment, and six were hormonal contraception users. They were given CZK 100 (approx. $4 €$ ) in compensation for their travel costs and time.

\section{Raters}

Axillary odour-perfume blends were rated by twenty women (mean age 24.5 years; SD = 2.8; range 20 to 30 years). They were recruited either personally among the students of 
Charles University in Prague or via an online advertisement. All women reported no olfactory impairment and were hormonal contraception users. They were given a bookstore voucher in the value of CZK 100 (approx. $4 €$ ) as a compensation for their participation.

As in Study 1, we recruited an additional 20 women (hormonal contraception users only) and 21 men to rate the pure perfume samples. Women's mean age was 22.8 years (SD = 3.7; range 18 to 35 years), men's was 24.0 years ( $\mathrm{SD}=2.9$; range 20 to 31 years). Men and women did not significantly differ in their age. All raters were reimbursed with CZK 100 (approx. $4 €$ ).

\subsubsection{Experimental design}

\section{Perfume selection}

As in Study 1, each participant arrived separately (this time, from their sister) at our laboratory, at an arranged time. The procedure of perfume selection was the same: participants chose two perfumes out of six in the first part and one perfume out of eight in the second part (men again chose for themselves; but here women chose for their brothers). During the break, participants completed a demographic questionnaire and reported quality of the relationship with their sibling on a 7-point scale. However, their answers showed very low variation (66.6\% reported the highest quality and the rest the second highest quality) which precluded their use in further analysis. 


\section{Odour collection}

The odour sampling procedure was identical to that in Study 1. When asking about their conformity with the instructions, one donor reported that he slept in the same bed with his partner, another donor used deodorant on both days and two donors consumed a small amount of alcohol.

\section{Rating session}

The rating session started immediately after all samples were collected. The main aspects of the rating session were identical to Study 1. It took place in a quiet and ventilated room with relatively constant temperature (about $20^{\circ} \mathrm{C}$ ) and humidity (about $40 \%$ ). To maintain the same number of samples, we used the control samples from Study 1 (i.e., the samples from the man who selected the same perfume as his partner).

In a separate session, we also tested the pure perfume samples. The rating procedure was the same as in Study 1. Testing ran over two consecutive days, each time with fresh samples. On the first day, we collected ratings from 15 men and 11 women, and on the second, we collected data from 6 men and 9 women.

\subsection{Statistical analysis}


First, we compared the ratings of body odour-perfume blends for those comprising perfumes chosen by men and by their partners/sisters. Kolmogorov-Smirnov tests showed that the data followed a normal distribution, allowing us to use paired t-tests for the analyses, with raters as the unit of analysis. We employed repeated measures ANOVA for the comparison of pure perfume samples with the rater's sex as a between-subject factor and perfume selected by the target men and his partner/sister as a repeated measure. In both cases, raters were used as units of analyses. Bivariate correlations among rated variables were computed using Pearson's correlation coefficient with individual observations as units of analyses. To test whether the target man-romantic partner/sister dyads selected the same perfume at frequencies higher than expected by a chance, we compared the observed and expected counts of dyads choosing the same/different perfume by the Chi square test with Yates correction. The expected counts were computed from the actual frequencies of perfumes selected by target men and their romantic partners/sisters. The same procedure was used for testing frequencies of selection of the perfume categories. We did not perform adjustments for multiple tests as we tested specific hypotheses (in contrast to the universal null hypothesis). In such cases, adjustments are not recommended for they inflate the chance of type II error (Perneger 1998). The statistical package SPSS 20 was used for all data analysis.

\section{Results}




\subsection{Study 1}

First, we compared the assessments of body odours blended with the perfumes chosen by men themselves and by their partners. We found no significant differences in the ratings of attractiveness $\left(\mathrm{t}_{19}=1.77 ; \mathrm{p}=0.093\right)$, masculinity $\left(\mathrm{t}_{19}=1.299 ; \mathrm{p}=0.21\right)$, and intensity $\left(\mathrm{t}_{19}=\right.$ $1.765 ; \mathrm{p}=0.094)$. The differences in pleasantness ratings approached the formal level of significance $\left(\mathrm{t}_{19}=2.084 ; \mathrm{p}=0.051\right)$ : the body odour samples blended with the perfumes chosen by their female partners were rated as more pleasant than the samples with the perfumes chosen by the men themselves (Figure 2a). As expected, in the case of control samples, i.e., the axillary odours from one man blended with the same perfume, we found no significant differences in any of the rated variables (all p's $>0.27$ ).

Additionally, we compared the ratings of pure perfume samples. Repeated measures ANOVA revealed a significant main effect of the rater's sex in the ratings of pleasantness $\left(\mathrm{F}_{1,40}=4.429 ; \mathrm{p}=0.042 ;\right.$ partial eta $\left.{ }^{2}=0.1\right)$ with men giving higher ratings on average. However, no similar effect of the rater's sex was observed in the ratings of attractiveness $\left(\mathrm{F}_{1,40}=1.155 ; \mathrm{p}=0.289\right)$, masculinity $\left(\mathrm{F}_{1,40}=3.803 ; \mathrm{p}=0.058\right)$, and intensity $\left(\mathrm{F}_{1,40}=\right.$ $1.735 ; \mathrm{p}=0.195)$. Further, we found no significant differences in the ratings of pleasantness $\left(\mathrm{F}_{1,40}=0.066 ; \mathrm{p}=0.799\right)$, attractiveness $\left(\mathrm{F}_{1,40}=1.134 ; \mathrm{p}=0.293\right)$, masculinity $\left(\mathrm{F}_{1,40}=1.88 ; \mathrm{p}=0.178\right)$, and intensity $\left(\mathrm{F}_{1,40}=0.631, \mathrm{p}=0.432\right)$ between the 
perfumes selected by the target men and their female partners. Similarly, we found no significant effect of the interaction between the rater's sex and ratings of pleasantness $\left(\mathrm{F}_{1,40}\right.$ $=0.219 ; \mathrm{p}=0.643)$, attractiveness $\left(\mathrm{F}_{1,40}=0.137 ; \mathrm{p}=0.713\right)$, masculinity $\left(\mathrm{F}_{1,40}=0.367 ; \mathrm{p}\right.$ $=0.548)$, and intensity $\left(\mathrm{F}_{1,40}=0.004 ; \mathrm{p}=0.948\right)$ of the perfumes selected by the target men and their female partners (Figure 2b). The relationship between the rated variables (pleasantness, attractiveness, masculinity, intensity) was analysed separately for the blends and pure perfume samples by Pearson's correlation analysis; for the results see Table 2 .

Table 2: Pearson's correlations and respective p-values (in italics) between rated variables in the Study 1. The values above the diagonal show correlations between the ratings of the body odour-perfume blends, the values below the diagonal show correlations between the ratings of the perfumes alone (for both male and female raters).

\begin{tabular}{|l|l|l|l|l|}
\hline & Pleasantness & Attractiveness & Masculinity & Intensity \\
\hline Pleasantness & & 0.93 & -0.02 & -0.17 \\
& & $<0.001$ & 0.59 & $<0.001$ \\
\hline Attractiveness & 0.84 & & -0.01 & -0.15 \\
& $<0.001$ & & 0.75 & 0.001 \\
\hline Masculinity & -0.08 & -0.01 & & 0.21 \\
& 0.008 & 0.68 & & 0.00 \\
\hline Intensity & -0.17 & -0.05 & 0.12 & \\
& $<0.001$ & 0.11 & $<0.001$ & \\
\hline
\end{tabular}

Subsequently, we tested whether the frequency when both partners selected the perfume from the same category or the same perfume was higher than chance. A perfume from the same category was chosen in 6 out of $16(37.5 \%)$ cases which is significantly higher than 
chance (Yates' Chi-square $=4.267 ; \mathrm{p}=0.039$ ). Similarly, the same perfume was chosen in 4 out of 16 cases $(25 \%)$, also significantly higher than chance (Yates' Chi-square $=9.365 ; \mathrm{p}$ $=0.002$ ). For the frequency of selection of different perfume categories see Table 3 .

Table 3: Perfume categories selected by target men and their partners (Study 1) and by target men and their sisters (Study 2). Please note that the table includes 4 couples from Study 1 who selected the same perfume and were excluded from the other analysis.

\begin{tabular}{|l|l|l|l|l|l|}
\hline \multirow{2}{*}{} & \multicolumn{4}{c|}{ Count (frequency in \%) of selection } \\
\cline { 2 - 5 } & \multicolumn{2}{|c|}{ Study 1 } & \multicolumn{2}{c|}{ Study 2 } & \multirow{2}{*}{ In total } \\
\hline $\begin{array}{c}\text { Perfume } \\
\text { categories }\end{array}$ & Target men & \multicolumn{1}{|c|}{ Partners } & Target men & \multicolumn{1}{|c|}{ Sisters } & \\
\hline Fougère & $2(12.5)$ & $2(12.5)$ & $3(25)$ & $1(8.3)$ & $8(14,3)$ \\
\hline Woody & $2(12.5)$ & $0(0)$ & $1(8.3)$ & $2(16.7)$ & $5(8,9)$ \\
\hline Aquatic & $3(18.8)$ & $2(12.5)$ & $2(16.7)$ & $3(25)$ & $10(17,9)$ \\
\hline Citrus/cologne & $3(18.8)$ & $4(25)$ & $3(25)$ & $4(33.3)$ & $14(25)$ \\
\hline Oriental & $4(25)$ & $1(6.3)$ & $0(0)$ & $0(0)$ & $5(8,9)$ \\
\hline Aromatic & $2(12.5)$ & $7(43.8)$ & $3(25)$ & $2(16.7)$ & $14(25)$ \\
\hline
\end{tabular}

\subsection{Study 2}

In the second experiment, we compared the ratings of the body odour samples blended with the perfume chosen either by men themselves or by their sisters. We found no significant differences in the ratings of pleasantness $\left(\mathrm{t}_{19}=1.353 ; \mathrm{p}=0.192\right)$, masculinity $\left(\mathrm{t}_{19}=1.983\right.$; $\mathrm{p}=0.062)$, and intensity $\left(\mathrm{t}_{19}=0.501 ; \mathrm{p}=0.622\right)$. However, we found a significant 
difference in the ratings of attractiveness $\left(\mathrm{t}_{19}=2.966, \mathrm{p}=0.008\right)$ (Figure 3a), with the blends of body odour and perfume chosen by sisters rated as more attractive than the blends including the man's self-chosen perfume. When we analysed the data from the control samples, we again, as expected, found no significant differences in any of the rated variables (all p's $>0.4)$.

As in Study 1, we then compared the ratings of pure perfume samples. Using repeated measures ANOVA, we found no significant main effect of the rater's sex in ratings of pleasantness $\left(F_{1,39}=0.461 ; p=0.501\right)$, attractiveness $\left(F_{1,39}=0.071 ; p=0.791\right)$, and intensity $\left(F_{1,39}=0.487 ; p=0.489\right)$. However, women gave significantly higher ratings of masculinity $\left(\mathrm{F}_{1,39}=12.910 ; \mathrm{p}=0.001\right.$; partial eta $\left.{ }^{2}=0.249\right)$ when compared to the male raters. The differences in pleasantness ratings of pure perfume samples selected by the target men and their sisters approached the formal level of significance $\left(\mathrm{F}_{1,39}=4.003 ; \mathrm{p}=\right.$ 0.052) with the perfumes selected by the sisters being rated as more pleasant. The ratings of masculinity of the perfumes selected by the sisters were significantly higher when compared to the ratings of perfumes selected by the target men $\left(F_{1,39}=12.061 ; p=0.001\right.$; partial eta ${ }^{2}=0.236$ ). However, we found no significant differences in the ratings of attractiveness $\left(\mathrm{F}_{1,39}=1.434 ; \mathrm{p}=0.238\right)$ and intensity $\left(\mathrm{F}_{1,39}=0.926 ; \mathrm{p}=0.342\right)$ between the perfumes selected by the target men and their sisters (Figure 3b). Also, we found no significant effect of the interaction between the rater's sex and ratings of pleasantness $\left(\mathrm{F}_{1,39}\right.$ $=0.341 ; \mathrm{p}=0.563)$, attractiveness $\left(\mathrm{F}_{1,39}=1.937 ; \mathrm{p}=0.172\right)$, masculinity $\left(\mathrm{F}_{1,39}=0.762 ; \mathrm{p}=\right.$ 
$0.388)$, and intensity $\left(\mathrm{F}_{1,39}=0.038 ; \mathrm{p}=0.846\right)$ of the perfumes selected by the target men and their sisters. We also analysed the correlations between the rated variables in the same way as in Study 1; for results see Table 4.

Subsequently, we tested whether the frequency when the target man and his sister selected a perfume from the same category was higher than chance. A perfume from the same category was chosen in 3 out of $12(25 \%)$ cases which is not significantly higher than chance. None of the brother-sister dyads selected the same perfume.

Table 4: Pearson's correlations and respective p values (in italics) between rated variables in Study 2. The values above the diagonal show correlations between the ratings of the body odour-perfume blends, the values below the diagonal show correlations between the ratings of the perfumes alone (for both male and female raters).

\begin{tabular}{|l|l|l|l|l|}
\hline & Pleasantness & Attractiveness & Masculinity & Intensity \\
\hline Pleasantness & & $\begin{array}{l}0.87 \\
<0.001\end{array}$ & $\begin{array}{l}-0.04 \\
0.44\end{array}$ & $\begin{array}{l}-0.22 \\
<0.001\end{array}$ \\
& & & 0.05 & -0.14 \\
Attractiveness & 0.82 & & 0.25 & 0.001 \\
& $<0.001$ & 0.05 & & 0.26 \\
& 0.01 & 0.15 & & $<0.001$ \\
\hline Masculinity & 0.74 & -0.14 & 0.16 & \\
& -0.19 & $<0.001$ & $<0.001$ & \\
\hline Intensity & $<0.001$ & & & \\
& & &
\end{tabular}

\section{Discussion}


The main aim of this research was to test the effect of biological relatedness on perfume choice. Therefore, in Study 1 we compared the hedonic ratings of body odour blended with the perfume selected by the target men and their female partners. Similarly, in Study 2 we compared the selection of perfumes by the target men and their biological relatives (i.e., sisters). As body odours of related individuals share some similarities (Porter et al., 1985; Roberts et al., 2005; Weisfeld et al., 2003), we hypothesised that male body odour blended with the perfume selected by men themselves, would be rated as more attractive compared to the same body odour blended with the perfume selected by their romantic partner. We further expected that the body odour blended with the perfume selected by the target men themselves would be rated similarly attractive as the same body odour blended with the perfume selected by their sisters. These predictions were based on the results from former studies showing that humans appear to select perfumes that complement their individual body odour (Milinski \& Wedekind, 2001; Hämmerli et al., 2012; Lenochová et al., 2012). Contrary to these predictions, we found that body odour blended with the perfume selected by their sisters was rated significantly more attractive than the blends involving the perfume selected by the target men. One may speculate whether this pattern can be explained by inclusive fitness theory. In other words, sisters might be tuned for selecting well-fitting perfumes for their siblings which would increase the attractiveness of their brothers and thus potentially also increase their inclusive fitness. However, a similar trend, though not significant, was observed in Study 1, where body odours blended with the 
perfume selected by men's partners were rated as slightly more pleasant compared to the blends with perfume selected by the target men. This raises the question of whether the effect is specific to sisters. However, we were not able to explore this further as a direct comparison between the selections made by the partners and sisters was not possible in our study.

Nevertheless, one could also argue that the relatively higher attractiveness ratings given to the blends with perfumes selected by sisters might be attributed to the fact that women may simply prefer different perfumes than men do. This would be further supported by the above-mentioned findings regarding the similar, but not significant effect in partners (Study 1). To test this suggestion we conducted control rating sessions with the same set of pure perfumes (this time not blended with body odour) employing both male and female raters. In these analyses, we found no significant differences between the ratings given to the perfumes selected by men and their romantic partners. Interestingly, both female and male raters perceived perfumes selected by the sisters as significantly more masculine compared to the perfumes selected by target men. Thus, these findings do not support the interpretation that the observed pattern in assessment of blends can be explained by sex differences in perfume preferences. We employed only women as the perfume-body odour blends raters because we assumed that the "olfactory adornment" is primarily directed to the opposite sex individuals, although this might not necessarily be the case and intersexual competition could also be involved. Perhaps men and women use different criteria for 
selection, wherein women choose perfumes with higher social significance for other women and men choose perfumes with higher social significance for other men. Thus, future studies should employ raters of both sexes.

Another possible explanation for our results could lie in the more complex olfaction-related cognitive abilities of women. Specifically, it might be easier for women to imagine the resulting body odour-fragrance blend than for the man himself to do so and thus be better at selecting the perfume that would suit the target man more. Women tend to outperform men in various aspects of olfactory perception (for review, see Doty and Cameron, 2009) and are reported to put more emphasis than men do on smell in their assessment of potential partners (Herz \& Inzlicht, 2002; Havlicek et al., 2008). Nevertheless, a recent study found no gender difference in olfactory imagination (Köster et al., 2014).

In $25 \%$ of cases we observed that romantic partners selected the same perfume; a rate which is highly unlikely to occur by chance. Similarly, we found that the partners more frequently selected perfumes from the same category. Interestingly, similar agreement was not observed in brother-sister dyads where the number of sisters who selected the perfume from the same category as their brothers did not differ from chance. This is at odds with our predictions as we had expected that sisters would select more suitable perfumes for their brothers compared to the romantic partners. If true, a higher congruency between the siblings should also occur, which was not the case here. One possible interpretation of these 
findings is that the romantic partners were more familiar with their partners' perfume preferences. Although we specifically recruited men who were not regular perfume users, it is possible that some of them actually were using perfume and their partner was thus familiar with it.

It is commonly reported that intensity and pleasantness of body odours are negatively correlated (Havlíček et al., 2006; Doty, Green, Ram \& Yankell, 1982; Doty, Orndorff, Leyden \& Kligman, 1978). Our results corroborate these findings although the association was rather moderate. The negative correlation between the rated intensity and pleasantness was not restricted to the body odour-perfume blends but a similar pattern was also observed in the ratings of the pure perfume samples. Interestingly, this association appears to be restricted to some conditions. For example, Wedekind, Seebeck, Bettens and Paepke (1995) found that women rated intense body odours of MHC-dissimilar men as unpleasant, but no correlation was found in the odours of men with similar MHC. The results of another study showed that women rated more intense male body odours as "more sexy" when they were in the fertile phase of the cycle but this was not the case in their non-fertile phase of the cycle (Rikowski \& Grammer, 1999). In our study, we employed as raters of the body odour-perfume blends only women using hormonal contraception, and thus we cannot test for a cycle effect. However, the results and the moderate association between intensity and pleasantness found here indicate that the pleasantness ratings cannot be fully accounted for by the intensity of the body odour. 
From a methodological perspective, one of the main challenges of this research was to provide a set of perfumes which would adequately represent the variation in the perfumes available on the market. Currently, there is no common agreement among experts on classification of fragrances (Donna, 2009). The set employed in our studies was based on the Osmoz classification system. This system classifies perfumes into 6 main categories, each containing 4 subcategories, and is considered to cover the full variability of perfumes available on the market. Each of these subcategories was represented by one perfume (i.e., 24 perfumes in total). The selected perfumes were aimed to represent the most typical fragrance of the respective subcategory. The selection of the representative perfumes was extensively consulted with professional perfumers. In general, we found this approach to be successful and potentially applicable for other studies on perfume choice as well.

Another methodological challenge concerned the method of perfume selection made by the participants as olfactory based decisions are relatively unreliable after repeated exposure. Therefore, we developed a two-step selection procedure (see methods section for details). This allowed us to include the entire set of perfumes without unduly burdening our raters. However, this approach might be also burdened with some disadvantages. More specifically, the data analysis comparing preferences of the individual perfumes showed that perfumes representing the main categories were selected significantly more often than the other representatives of the given category. These were the perfumes that participants 
assessed during both the first and the second step. It is thus possible that selection bias for these perfumes could be ascribed to the "mere exposure effect" which occurs when an individual is repeatedly exposed to a particular stimulus object, which in turn causes individual's emerging preference for that object (Zajonc, 2001). Alternatively, the preference for the most typical perfumes might be due to their high similarity to a mental representation of that particular category. Based on our data, we are unable to decide between these two alternatives and this issue should be further explored.

To avoid possible fluctuations in olfactory processing during the menstrual cycle (Martinec Nováková et al., 2014), we recruited only female raters who were using hormonal contraception. Nevertheless, results of previous studies indicate that hormonal contraception could influence women's olfactory preferences. In particular, women using hormonal contraception tended to prefer body odour of MHC similar men which was in contrast to women not using the hormonal contraception, who preferred odour of MHCdissimilar men (Roberts, Gosling, Carter \& Petrie 2008; Wedekind et al., 1995). Similarly, Milinski and Wedekind (2001) noted that users of hormonal contraception were more sensitive to the fragrances correlated with the different types of MHC than non-users were. Future studies should thus address how the pattern found here can be generalized to women not using hormonal contraception. 
In our studies, we focused on men as target individuals to avoid cyclic variation of the women's body odour (Singh \& Bronstad, 2001; Kuukasjärvi et al., 2004; Havlíček et al., 2006). The perfume selection made by the target men was subsequently compared with the perfume selection by either their romantic partners (Study 1) or their sisters (Study 2). Our original aim was to recruit target man-partner-sister triads which would enable us to make direct comparisons between the choices of partners and sisters. However, this turned out to be logistically impossible, and we therefore had to run the tests separately. This remains a challenge for future studies. Similarly, it appears to be important to perform a study employing women as the target individuals to test whether we would see a similar pattern as found here. Furthermore, to avoid a possible influence of the participants' sex on perfume preferences, as discussed above, it would be interesting to conduct a study which would employ only participants of the same sex (e.g., men and their brothers or friends). Finally, the perfume-body odour blends were assessed for their hedonicity and intensity but not for familiarity. This might potentially affect current findings as it was shown that familiar odours are perceived as more pleasant (Royet et al. 1999), though this effect might be restricted to unpleasant odours only (Martinec Nováková, Plotěná, Roberts \& Havlíček, 2015).

As discussed above, our research was guided by studies on perfume and body odour interactions. However, perfume preferences might be affected by other factors as well. For example, Mensing and Beck (1988) found that perfume choice is also linked to personality 
type (compared to introverts, extraverted individuals preferred different perfume types). Other studies have shown the effect of age on fragrance preferences (Lambert-Pandraud, Laurent \& Sodini, 2006; Lambert-Pandraud \& Laurent, 2010). This reinforces the fact that perfume choice appears to be a complex and multivariate process, and it might be therefore possible that the expected effect of biological relatedness was overridden by other factors not controlled for here.

In summary, based on previous studies showing that perfumes are chosen to complement one's body odour, we expected that target individuals would select perfumes which would suit them more as compared to the selection made by their romantic partners. In contrast, we predicted no differences in the selections made by the target individual and their biological relatives (sisters). Thus, in the two studies, we compared the assessment of body odour-perfume blends chosen by target men and their girlfriends or by target men and their sisters. Contrary to our expectation, the body odours blended with perfumes chosen by men were rated as less attractive as compared to the perfumes selected by sisters; an effect that could perhaps reflect that sisters prefer odours that match products of their own genes (that are similar to their brothers genes). The generalizability of these findings should be explored by future studies.

\section{Acknowledgements}


We would like to thank all the volunteers for their participation, Jana Jirousková from Aroma Praha a.s. and Kate Williams and her colleagues from Seven Scent Ltd. for their help with creating the perfume set, Helena Pšeničková for the help with the data digitalization and Jinka Boušová for her extremely helpful comments on earlier version of the paper. The study was supported by the Czech Science Foundation (GA14-02290S) and the Charles University Grant Agency (GAUK 918214).

\section{Declaration of Conflicting Interests}

All authors declare that they have no conflict of interest.

\section{Author contributions}

Conceived and designed the experiments: MG, JF, JH, SCR. Performed the experiments: MG, JF. Analysed the data: MG, JH. Wrote the paper: MG, JH, SCR.

\section{References}

Allen, C., Havlíček, J. and Roberts, S. C. (2015). Effect of fragrance use on discrimination of individual body odour. Front. Psychol. 6, 1115. doi:10.3389/fpsyg.2015.01115. 
Allen, C., Cobey, K. D., Havlíček, J., and Roberts, S. C. (2016). The impact of artificial fragrance use on the detection of mate quality cues present in body odour. Evol. Hum. Behav. 37, 481-489. doi: 10.1016/j.evolhumbehav.2016.05.001

Anonymous (2015). Flavor \& Fragrance Industry Leaders. Leffingwell \& Associates. Available: http://www.leffingwell.com/top_10.htm. Accessed 2015, January 21.

Baron, R. A. (1983). "Sweet smell of success"? The impact of pleasant artificial scents on evaluations of job applicants. J. Appl. Psychol. 68, 709-713. doi: 10.1037/00219010.68.4.709

Baron, R. A. (1986). Self-presentation in job interviews: When there can be "too much of a good thing". J. Appl. Soc. Psychol. 16, 16-28. doi: 10.1111/j.1559-1816.1986.tb02275.x

Cernoch, J. M, and Porter, R. H. (1985). Recognition of maternal axillary odours by infants. Child. Dev., 56, 1593-1598.

Donna, L. (2009). Fragrance perception: Is everything relative. Perfumer \& Flavorist 34, 26-35.

Doty, R. L., and Cameron, E. L. (2009). Sex differences and reproductive hormone influences on human odour perception. Physiol. Behav. 97, 213-228.

doi:10.1016/j.physbeh.2009.02.032 
Doty, R. L., Green P. A., Ram C., and Yankell, S. L. (1982). Communication of gender from human breath odours: relationship to perceived intensity and pleasantness. Horm. Behav. 16, 13 -22. doi:10.1016/0018-506X(82)90002-2

Doty, R. L., Orndorff, M. M., Leyden, J., and Kligman, A. (1978). Communication of gender from human axillary odours: relationship to perceived intensity and hedonicity. Behav. Biol. 23, 373-380. doi:10.1016/S0091-6773(78)91393-7

Ferdenzi, C., Schaal, B., and Roberts, S. C. (2009). Human axillary odour: Are there siderelated perceptual differences? Chem. Senses 34, 565-571. doi: 10.1093/chemse/bjp037.

Fialová, J., and Havlíček, J. (2012). Perception of emotion-related body odours in humans. Anthropologie 50, 95-110.

Fialová, J., Roberts, S. C., and Havlíček, J. (2016). Consumption of garlic positively affects hedonic perception of axillary body odour. Appetite. 97, 8-15. doi:10.1016/j.appet.2015.11.001

Garver-Apgar, C. E., Gangestad, S. W., Thornhill, R., Miller, R. D., and Olp, J. J. (2006). Major histocompatibility complex alleles, sexual responsivity, and unfaithfulness in romantic couples. Psychol. Sci. 17, 830-835. doi:10.1111/j.1467-9280.2006.01789.x 
Hämmerli, A., Schweizgut, C., and Kaegi, M. (2012). Population genetic segmentation of MHC-correlated perfume preferences Int. J. Cosmetic Sci. 34, 161 - 168.

doi: 10.1111/j.1468-2494.2011.00696.x

Havlíček, J., Dvořáková, R., Bartoš, L., and Flegr, J. (2006). Non-advertized does not mean concealed: Body odour changes across the human menstrual cycle. Ethology 112, 81-90. doi: 10.1111/j.1439-0310.2006.01125.x

Havlicek, J., and Lenochova, P. (2008). "Environmental effects on human body odour", in Chemical Signals in Vertebrates 11, eds J. L. Hurst, R. J. Beynon, S. C. Roberts, and T. D. Wyatt (Springer, New York), 199-210.

Havlíček, J., Lenochová, P., Oberzaucher, E., Grammer, K., and Roberts, S. C. (2011). Does length of sampling affects quality of body odour samples? Chemosens. Percept. 4, 186-194. doi: 10.1007/s12078-011-9104-6

Havlicek, J., and Roberts, S. C. (2009). MHC-correlated mate choice in humans: a review. Psychoneuroendocrinol. 34, 497-512. doi:10.1016/j.psyneuen.2008.10.007

Havlíček, J., and Roberts, S. C. (2013). "Perfume-body odour complex: An insightful model for culture-gene coevolution?", in Chemical Signals in Vertebrates XII, eds. M. L. East, and M. Dehnhard (Springer, New York), 185-196. doi: 10.1007/978-1-4614-5927$9 \_14$ 
Havlicek, J., Saxton, T. K., Roberts, S. C., Jozifkova, E., Lhota, S., Valentova, J. et al. (2008). He sees, she smells? Male and female reports of sensory reliance in mate choice and non-mate choice contexts. Pers. Indiv. Differ. 45, 565-570. doi:

10.1016/j.paid.2008.06.019

Herz, R. S., and Inzlicht, M. (2002). Sex differences in response to physical and social factors involved in human mate selection: The importance of smell for women. Evol. Hum. Behav. 23, 359-364. doi:10.1016/S1090-5138(02)00095-8

Kohoutová, D., Rubešová, A., and Havlíček, J. (2012). Shaving of axillary hair has only a transient effect on perceived body odour pleasantness. Behav. Ecol. Sociobiol. 66, 569-581. doi: 10.1007/s00265-011-1305-0.

Köster, E. P., Van der Stelt, O., Nixdorf, R. R., Linschoten, M. R. I., de Wijk, R. A., and Mojet, J. (2014). Olfactory imagination and odor processing: three same-different experiments. Chemosens. Percept., 7, 68-84.

Kuukasjärvi, S., Eriksson, C. P., Koskela, E., Mappes, T., Nissinen, K., and Rantala, M. J. (2004). Attractiveness of women's body odours over the menstrual cycle: the role of oral contraceptives and receiver sex. Behav. Ecol. 15, 579-584. doi: 10.1093/beheco/arh050

Lambert-Pandraud, R., Laurent, G., and Sodini, P. (2006). Tell me which perfume you wear, I'll tell you how old you are: Modeling the impact of consumer age on product choice. Chambre de Commerce et d'Industrie de Paris. 
Lambert-Pandraud, R., and Laurent, G. (2010). Why do older consumers buy older brands? The role of attachment and declining innovativeness. J. Marketing 74, 104-121. doi: 10.1509/jmkg.74.5.104

Lenochova, P., and Havlicek, J. (2008). "Human body odour individuality", in Chemical Signals in Vertebrates 11, eds J. L. Hurst, R. J. Beynon, S. C. Roberts, and T. D. Wyatt (Springer, New York), 189-198. doi: 10.1 007/978-0-387-73945-8_18

Lenochova, P., Roberts, S. C., and Havlicek, J. (2009). Methods of human body odour sampling: The effect of freezing. Chem. Senses 34, 127-138. doi: 10.1093/chemse/bjn067

Lenochová, P., Vohnoutová, P., Roberts, S. C., Oberzaucher, E., Grammer, K., and Havlíček, J. (2012). Psychology of fragrance use: perception of individual odour and perfume blends reveals a mechanism for idiosyncratic effects on fragrance choice. PLoS One 7, e33810. doi: 10.1371/journal.pone.0033810

Martinec Nováková, L., Havlíček, J., and Roberts, S. C. (2014). Olfactory processing and odour specificity: a meta-analysis of menstrual cycle variation in olfactory sensitivity. Anthropol. Rev. 77, 331-345.

Martinec Nováková, L., Plotěná, D., Roberts, S. C., and Havlíček, J. (2015). Positive relationship between odour identification and affective responses of negatively valenced odours. Front. Psychol. 6, 607. doi:10.3389/fpsyg.2015.00607 
Mensing, J., and Beck, C. (1988). "The psychology of fragrance selection." in Perfumery. Springer Netherlands, 185-204. doi: 10.1007/978-94-009-1215-1_10

Milinski, M., and Wedekind, C. (2001). Evidence for MHC-correlated perfume preferences in humans. Behav. Ecol. 12, 140-149. doi: 10.1093/beheco/12.2.140

Olsson, M. J., Lundström, J. N., Kimball, B. A., Gordon, A. R., Karshikoff, B., Hosseini, N. et al. (2014). The scent of disease: Human body odour contains an early chemosensory cue of sickness. Psychol. Sci. 25, 817-823. doi: 10.1177/0956797613515681

Perneger, T. V. (1998). What's wrong with Bonferroni adjustments. Brit. Med. J. 316, $1236-1238$.

Porter, R. H., Cernoch, J. M., and Balogh, R. D. (1985). Odour signatures and kin recognition. Physiol. Behav. 34, 445-448.

Rikowski, A., and Grammer, K. (1999). Human body odour, symmetry and attractiveness. P. Roy. Soc. Lond. B Biol. 266, 869-874. doi: 10.1098/rspb.1999.0717

Roberts, S. C., Ferdenzi, C., Kralevich, A., Little, A. C., Jones, B. C., DeBruine, L. M. et al. (2011). Body odour quality predicts behavioral attractiveness in humans. Arch. Sex. Behav. 40, 1111-1117. doi: 10.1007/s10508-011-9803-8 
Roberts, S. C., Gosling, L. M., Spector, T. D., Miller, P., Penn, D. J., and Petrie, M. (2005).

Body odour similarity in noncohabiting twins. Chem. Senses 30, 651-656. doi:

10.1093/chemse/bji058

Roberts, S. C., Gosling, L. M., Carter, V., and Petrie, M. (2008). MHC-correlated odour preferences in humans and the use of oral contraceptives. P. Roy. Soc. Lond. B Biol. 275, 2715-2722. doi: 10.1098/rspb.2008.0825

Roberts, S. C., Little, A. C., Lyndon, A., Roberts, J., Havlicek, J., and Wright, R. L. (2009). Manipulation of body odour alters men's self-confidence and judgements of their visual attractiveness by women. Int. J. Cosmetic Sci. 31, 47-54. doi: 10.1111/j.14682494.2008.00477.x

Roberts, S.C., Petrie, M., and Havlíček, J. (2013). Repeatability of body odour preferences across time. Flavour Frag. J. 28, 245-250. doi: 10.1002/ffj.3142

Royet, J. P., Koenig, O., Gregoire, M. C., Cinotti, L., Lavenne, F., LeBars, D. et al. (1999). Functional anatomy of perceptual and semantic processing for odours. J. Cogn. Neurosci. 11, 94-109. doi:10.1162/089892999563166

Russell, M. J., Mendelson, T., and Peeke, H. V. S. (1983). Mother's identification of their infant's odours. Ethol. Sociobiol. 4, 29-31. doi:10.1016/0162-3095(83)90005-5 
Sczesny, S., and Stahlberg, D. (2002). The influence of gender-stereotyped perfumes on leadership attribution. Eur. J. Soc. Psychol. 32, 815-828. doi: 10.1002/ejsp.123

Schleidt, M. (1980). Personal odour and nonverbal communication. Ethol. Sociobiol 1, 225231.

Shirasu, M., and Touhara, K. (2011). The scent of disease: volatile organic compounds of the human body related to disease and disorder. J. Biochem. 150, 257-266. doi:

$10.1093 / \mathrm{jb} / \mathrm{mvr} 090$

Singh, D., and Bronstad, P. M. (2001). Female body odour is a potential cue to ovulation. P. Roy. Soc. Lond. B Biol. 268, 797-801. doi: 10.1098/rspb.2001.1589

Sorokowska, A., Sorokowski, P., and Szmajke, A. (2012). Does personality smell? Accuracy of personality assessments based on body odour. Eur. J. Pers. 26, 496-503.

Sorokowska, A., Sorokowski, P., and Havlíček, J. (2016). Body odour based personality judgments: The effect of fragranced cosmetics. Front. Psychol. 7: 530.

doi:10.3389/fpsyg.2016.00530

Spanier, G. B. (1976). Measuring of dyadic adjustment - new scales for assessing the quality of marriage and similar dyads. J. Marriage Fam. 38, 15-28. doi: 10.2307/350547 
Stoddart, D. M. (1990). The scented ape: the biology and culture of human odour. Cambridge University Press.

Thornhill, R., and Gangestad, S. W. (1999). The scent of symmetry: A human sex feromone that signals fitness? Evol. Hum. Behav. 20, 175-201. doi:10.1016/S10905138(99)00005-7

Thornhill, R., Gangestad, S. W., Miller, R., Scheyd, G., McCollough, J. K., and Franklin, M. (2003). Major histocompatibility complex genes, symmetry, and body scent attractiveness in men and women. Behav. Ecol. 14, 668-678. doi: 10.1093/beheco/arg043

Wedekind, C., Seebeck, T., Bettens, F., and Paepke, A. J. (1995). MHC-dependent mate preferences in humans. P. Roy. Soc. Lond. B Biol. 260, 245-249. doi:

10.1098/rspb.1995.0087

Weisfeld, G. E., Czilli, T., Phillips, K. A., Gall, J. A., and Lichtman, C. M. (2003). Possible olfaction-based mechanisms in human kin recognition and inbreeding avoidance. $J$. Exp. Child Psychol. 85, 279-295. doi:10.1016/S0022-0965(03)00061-4

Zajonc, R. B. (2001). Mere exposure: A gateway to the subliminal. Curr. Dir. Psychol. Sci. 10, 224-228. doi: 10.1111/1467-8721.00154 


\section{Figures Legends:}

\section{Figure 1:}

Schematic depiction of the two step perfume selection process used in both studies. In the first step the participant was asked to select two best smelling perfumes from six representing each main category. In this case, the participant selected the Aquatic and the Oriental categories. In the second step, the participant was asked to select the best smelling perfume from the 8 perfume subcategories which belong to the two categories selected in the step one. In this case, the participant selected the Oriental-woody subcategory.

Figure 2:

Ratings of pleasantness, attractiveness, masculinity and intensity of (a) the body odourperfume blends and (b) the pure perfumes (male and female raters together). The perfumes were selected by the target men (black bars) or by their romantic partners (grey bars). Error bars denoted SEM. Asterisk denoted $\mathrm{p}<0.05$.

\section{Figure 3:}

Ratings of pleasantness, attractiveness, masculinity and intensity of (a) the body odourperfume blends and (b) the pure perfumes (male and female raters together). The perfumes were selected by the target men (black bars) or by their sisters (grey bars). Error bars denoted SEM. Asterisk denoted $\mathrm{p}<0.05$. 
Fougère Aquatic Woody Citrus/Cologne Oriental Aromatic
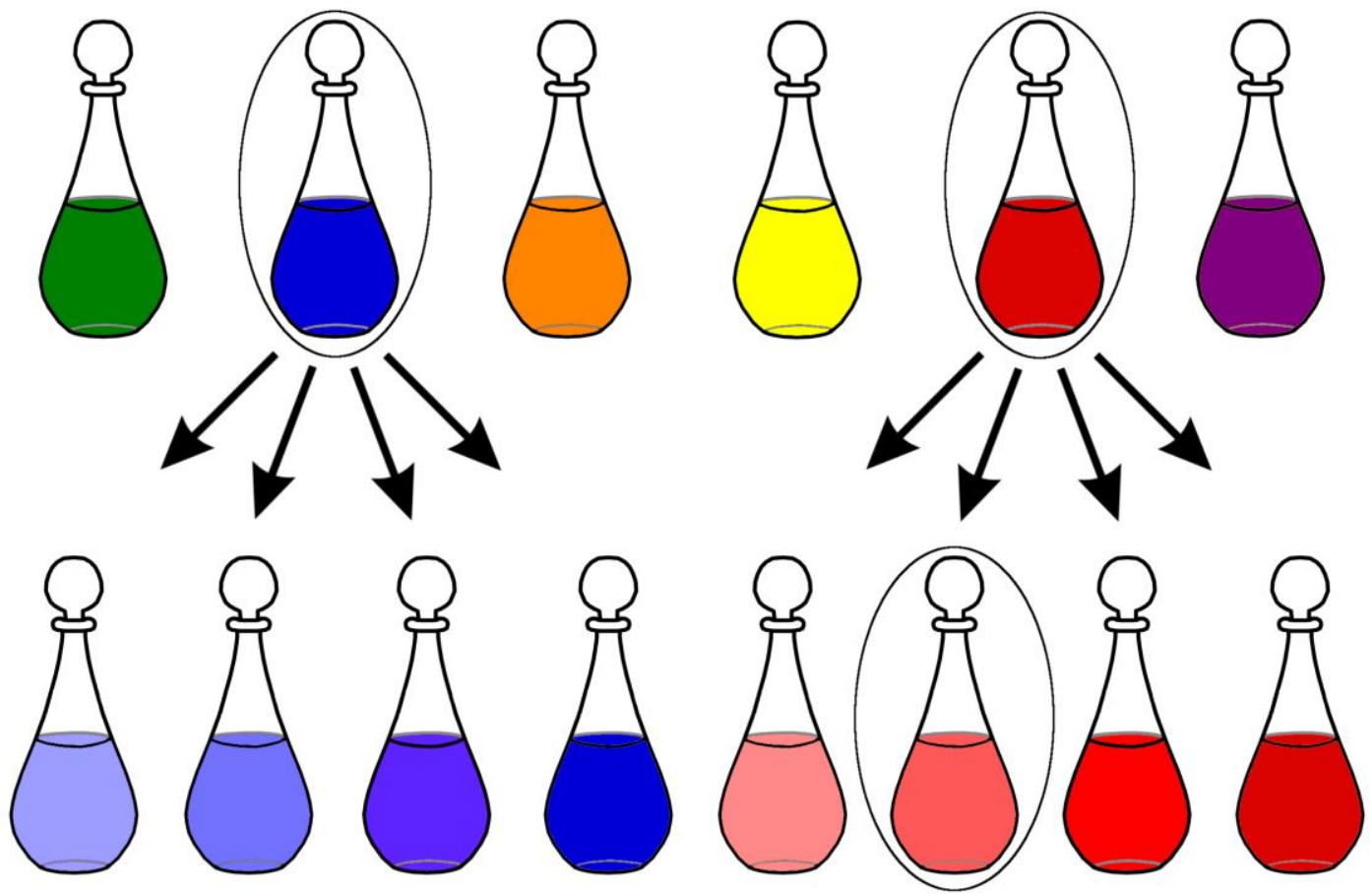

Aquatic Aquatic Aquatic Aquatic Fougère Citrus Woody

$\begin{array}{ccc}\text { Oriental } & \text { Oriental } & \text { Oriental } \\ \text { Citrus } & \text { Woody } & \text { Fougère }\end{array}$ 
a)

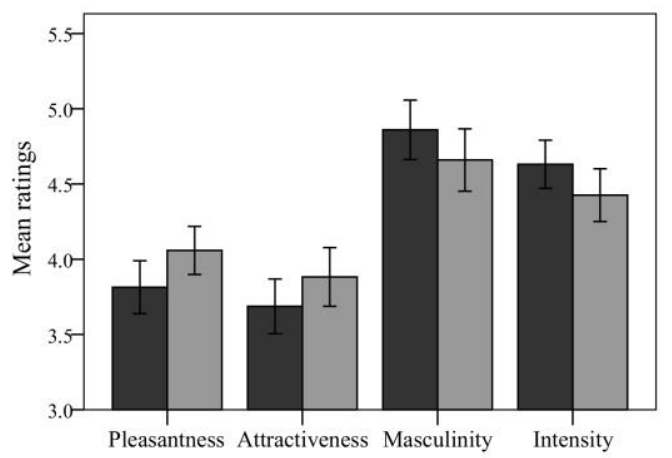

b)

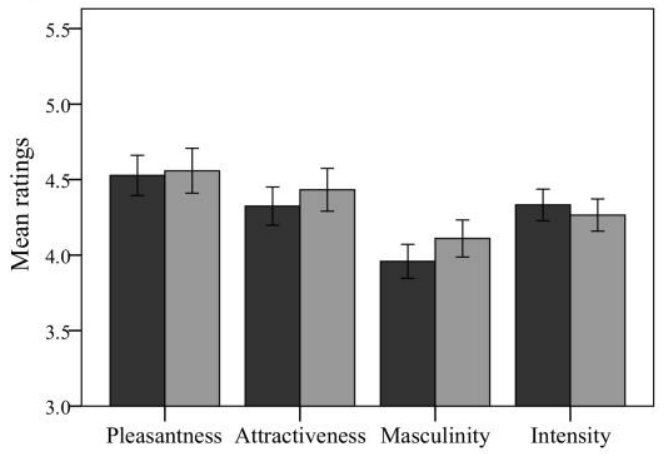



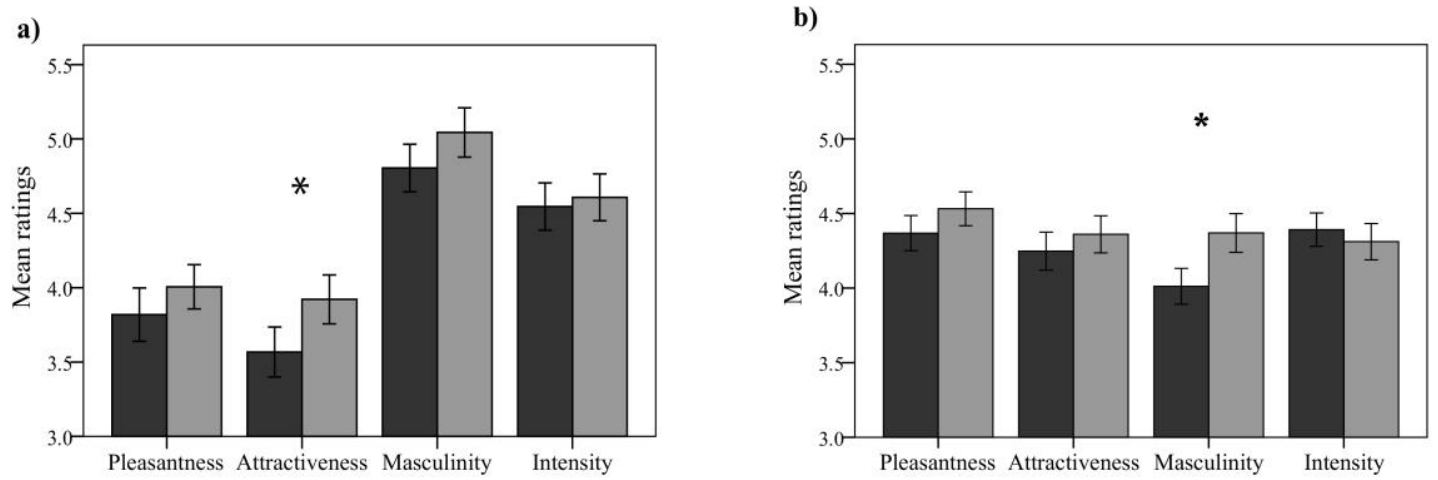